\title{
Weekly clinical synopsis: Piloting an innovative clinical teaching strategy
}

\author{
Nadia Ali Muhammad Ali Charania ${ }^{* 1}$, Bonnie M. Hagerty ${ }^{1}$, Laura A. Dansel ${ }^{1}$, Colwick M. Wilson ${ }^{2}$ \\ ${ }^{1}$ School of Nursing, University of Michigan, Ann Arbor, United States \\ ${ }^{2}$ Department of Social Work and Social Ecology, School of Behavioral Health, Loma Linda University, Loma Linda, United \\ States
}

Received: October 2, 2014

DOI: $10.5430 /$ jnep.v5n3p71
Accepted: November 5, 2014 Online Published: December 23, 2014

URL: http://dx.doi.org/10.5430/jnep.v5n3p71

\begin{abstract}
Clinical educators often struggle to provide ongoing and timely feedback to students. This article describes an innovative clinical teaching strategy, "weekly clinical synopsis" (WCS) which was piloted with four clinical groups $(\mathrm{n}=30)$. The premise of the WCS was based on Hysong, Best, and Pugh's model of actionable feedback. Both quantitative and qualitative findings complemented each other. Quantitatively, three WCS items were significant. Seeing others' accomplishments did not motivate students although some thought it helped them think about broadening their clinical accomplishments. The WCS significantly helped students to focus and complete assignments on time. Due to the nature of clinical feedback, some students were uncomfortable sharing their accomplishments. Qualitatively, students shared that the WCS created a connection between student and educator, provided a structure for clinical assignment, assisted in developing clinical goals, and limited a need to discuss clinical assignments. The WCS's strengths outweighed its limitations, and should be further tested.
\end{abstract}

Key Words: Clinical teaching strategy, Clinical feedback, Weekly clinical synopsis, Quantitative study, Qualitative study

\section{Introduction}

Clinical educators strive to create positive learning experiences for their students and to provide them with ongoing feedback on their clinical accomplishments and progress. Ongoing feedback is intended to assess the extent to which clinical objectives are met and to motivate students to make desired behavioral changes overtime.

Providing ongoing feedback and guidance are critical responsibilities for clinical educators; however many struggle to accomplish it. A review of the literature indicates that, in health care fields, clinical educators provide little to no feedback on students' clinical performance. ${ }^{[1,2]}$ Some clinical educators struggle just to provide some input let alone pro- vide timely, ${ }^{[1-4]}$ frequent, ${ }^{[5]}$ or ongoing input on students' accomplishments and areas where they need to pay attention to achieve specific clinical learning goals.

Empirical evidence also suggests that there are other areas where clinical educators sometimes fall short. These include but are not limited to clearly outlining performance criteria for evaluation, ${ }^{[1,2]}$ insuring that students clearly understand the difference between input on clinical learning and summative evaluation of their overall success or failure ${ }^{[6]}$ providing input on students' learning needs or expectations ${ }^{[5]}$ and accomplishments including their strengths in a positive way to enhance their performance, ${ }^{[7]}$ motivating, ${ }^{[8-12]}$ empowering, ${ }^{[13,14]}$ and bringing about desired behavioral changes needed to work independently and as a

\footnotetext{
* Correspondence: Nadia Ali Muhammad Ali Charania; Email: charania@umich.edu; Address: School of Nursing, University of Michigan, Ann Arbor, United States.
} 
team player in a clinical group. Clinical educators need to develop innovative ways to overcome these considerable challenges and continue to make an effort to develop partnerships with students that promote effective interpersonal relationships. ${ }^{[15]}$

This paper offers an innovative approach to clinical teaching, a "weekly clinical synopsis" (WCS), to address common issues associated with giving ongoing feedback on accomplishments and guidance to students on their clinical practice and related matters. The aims of this paper are to: 1) describe the development and use of WCS within the model of actionable feedback, 2) determine if there are differences in pre- and post-WCS surveys among students, and 3 ) describe students' perceptions of WCS.

\section{Conceptualizing the WCS}

The WCS was developed using the "model of actionable feedback". ${ }^{[16]}$ The clinical faculty conceived the strategy of WCS after reflecting on extensive clinical teaching experiences with nursing students both nationally and internationally. These experiences informed the belief that the whole clinical group including the faculty is a team working towards meeting learning objectives. Students and faculty work as partners in the learning journey. Faculty is primarily responsible for offering ongoing guidance and supporting and communicating expectations for clinical assignments. The focus of ongoing input is on students' weekly clinical accomplishments. Finally, students' accomplishments and progress towards clinical assignments are communicated in a positive tone, in a: (a) positive tone, (b) group format, and (c) timely manner.

WCS is defined as a document that clinical faculty write at the end of each clinical week and share with the whole clinical group within 24-48 hours. The document: (a) summarizes each student's clinical accomplishments, (b) specifically outlines assignments that each student needs to focus on in the following clinical week(s), (c) communicates potential learning opportunities, (d) shares faculty's and students' mutual decisions about deadlines for submitting assignments, (e) explicates assignment deadlines and faculty's expectations, (f) reinforces the importance of meeting clinical assignments in a timely manner, (g) ensures clinical continuity between clinical weeks, (h) motivates clinical group members to collaborate to bring everyone to the same level of learning and competence, and (i) does NOT mention any particular student's individual struggles/learning needs. Considering the purpose and understanding of WCS, a 10item pre-WCS survey (see Figure 1) and 11-item post-WCS survey were created (see Figure 2) to obtain students' views prior and after exposure to this clinical teaching strategy.
"A model of actionable feedback"[16] captures the premise of WCS. A model of actionable feedback evolved from a qualitative study that explored the differences between how high-and low-performing facilities deliver clinical audit data for feedback. Hysong, Best, and Pugh ${ }^{[16]}$ learned from their study that the higher the performing facility the more components of the model were incorporated in the feedback on clinical audit data.

The model of actionable (see Figure 3) feedback consisted of four key hierarchical components: a) timely, b) individualized, c) non-punitive, and d) customizable. The hierarchically ordered four components of the model when used to give feedback had an optimal effect on performance that aimed to support desired behavior change. ${ }^{[16]}$

Timeliness referred to the "frequency with which providers receive feedback". ${ }^{[16]}$ Hysong, Best, and Pugh ${ }^{[16]}$ argued that feedback must be provided in a timely manner for it to be useful. In the WCS strategy, the component of timeliness is highly valued; for it to be useful it must be shared shortly after the clinical day to help students plan for the following clinical week, achieve their clinical assignments as required, and ensure clinical continuity. The timeliness criterion for the WCS was considered acceptable if feedback was shared with the clinical group within 24-48 hours of completing the clinical week.

Individualized was referred to as "the degree to which providers receive feedback about their own individual performance, as opposed to aggregated data...". ${ }^{[16]}$ With respect to the WCS, individualization was used to the extent that it was relevant. Not all students received individualized feedback every week. However, over six weeks of clinicals, every student received individual recognition for their clinical accomplishments.

Non-punitive referred to "the tone with which the feedback is delivered" [16] Non-punitive feedback could increase the possibility that the recipient accepts it $^{[16]}$ and that it contributes to desired behavioral changes. The non-punitive component of the model is relevant to the premise of the WCS in that it focuses only on students' accomplishments and not on their specific learning need(s).

The last component of the actionable feedback model is customizable. "Customizability engages the individual with the data, making him/her an active participant in the sensemaking process, rather than a passive recipient of information". ${ }^{[16]}$ The WCS outlined assignments and explicated deadlines for each student to plan their following weekly clinicals, came up with their weekly clinical goals and made sense of the expectations and assignments. 
Feedback on A Clinical Teaching Strategy: WCS Survey Tool Students who NEVER received the weekly clinical synopsis

We would like you to first review the definition of a new clinical feedback strategy titled "Weekly Clinical Synopsis" then fill out a short survey. Your voluntary participation is much appreciated. Your anonymous feedback including comments will help clinical faculty to evaluate the strategy and assist them to make a decision about its future use with other clinical groups. Thank you!

\section{Weekly Climical Synopsis:}

A synopsis is a document written by a clinical faculty at the end of each clinical week and shared with the whole clinical group. A synopsis includes the following:
a. Summarizing and capitalizing on each student's accomplishments following the clinical experience each week.
b. Specifically outlining assignments for the student to focus on for the following clinical week(s).
c. Communicating potential leaming opportunities faculty created for students.
d. Explicating assignment deadlines and clinical faculty's expectations.
e. Reinforcing meeting clinical assignments in a timely manner.
f. Ensuring clinical continuity between clinical weeks.
9. Motivating clinical group members and bringing them all to their maximum capacity for learning and competence.
h. The goal is NOT to mention any particular student's struggles/learning needs.

\section{Feedback on WCS: Clinical Teaching Strategy}

Please indicate your agreement with the following statements by making a check in the box.

\begin{tabular}{|c|c|c|c|c|c|c|c|}
\hline$\#$ & A clinical synopsis: & $\begin{array}{l}\text { Strongly } \\
\text { disagree } \\
1\end{array}$ & $\begin{array}{l}\text { Disagree } \\
2\end{array}$ & $\begin{array}{l}\text { Neutral } \\
3\end{array}$ & $\begin{array}{l}\text { Agree } \\
4\end{array}$ & $\begin{array}{l}\text { Strongly } \\
\text { Agree } \\
5\end{array}$ & Comments \\
\hline 1. & $\begin{array}{l}\text { would allow me to see others' weekly accomplishments that } \\
\text { would motivate me to seek out similar leaming experiences }\end{array}$ & & & & & & \\
\hline 2. & $\begin{array}{l}\text { would feature planning for the following clinical week(s) } \\
\text { that would help me plan my own experience for my next } \\
\text { clinical }\end{array}$ & & & & & & \\
\hline 3. & $\begin{array}{l}\text { would feature weekly clinical assignments that would belp } \\
\text { me to focus and complete those assignments on time }\end{array}$ & & & & & & \\
\hline 4. & $\begin{array}{l}\text { would make me uncomfortable sharing my weekly clinical } \\
\text { accomplishments with my clinical group members }\end{array}$ & & & & & & \\
\hline 5. & $\begin{array}{l}\text { would make me uncomfortable sharing my weekly activities } \\
\text { to be accomplished with my clinical group members }\end{array}$ & & & & & & \\
\hline 6. & $\begin{array}{l}\text { would help me to develop realistic clinical goals for the } \\
\text { following week }\end{array}$ & & & & & & \\
\hline 7. & $\begin{array}{l}\text { would help me achieve at the same level as or higher than } \\
\text { the rest of my clinical group members }\end{array}$ & & & & & & \\
\hline 8. & would be a way of connecting with clinical group members & & & & & & \\
\hline 9. & would be a way of connecting with clinical faculty & & & & & & \\
\hline 10. & $\begin{array}{l}\text { would assist me in my clinical continuity and clinical } \\
\text { follow-up needs }\end{array}$ & & & & & & \\
\hline
\end{tabular}

Please state any comments about implementing the weekly written clinical synopsis for future clinicals:

Thank you!

Figure 1: Feedback on a clinical teaching strategy: WCS survey tool - students who never received the weekly clinical synopsis 


\section{Feedback on Clinical Teaching Tool: WCS Survey Tool} from students who RECEIVED weekly clinical synopsis

We would like you to review the definition of a new clinical feedback strategy titled "Weekly Clinical Synopsis" then fill out a short survey. Your voluntary participation is much appreciated. Your anonymous feedback including comments will help clinical faculty to evaluate the strategy and assist them to make a decision about its future use with other clinical groups. Thank you!

\section{Weekly Climical Synopsis:}

A synopsis is a document written by a clinical faculty at the end of each clinical week and shared with the whole clinical group. A synopsis includes the following:

a. Summarizing and capitalizing on each student's accomplishments following the clinical experience each week.

b. Specifically outlining assignments for the student to focus on for the following clinical week(s)

c. Communicating potential leaming opportunities faculty created for students.

d. Explicating assignment deadlines and clinical faculty's expectations.

e. Reinforcing meeting clinical assignments in a timely manner.

f. Ensuring clinical continuity between clinical weeks.

9. Motivating clinical group members and bringing them all to their maximum capacity for learning and competence.

h. The goal is NOT to mention any particular student's struggles/leaming needs.

\section{Feedback on WCS: Clinical Teaching Strategy}

Please indicate your agreement with the following statements:

\begin{tabular}{|c|c|c|c|c|c|c|c|}
\hline$\#$ & A clinical synopsis: & $\begin{array}{l}\text { Strongly } \\
\text { disagree } \\
1\end{array}$ & $\begin{array}{l}\text { Disagree } \\
2\end{array}$ & $\begin{array}{l}\text { Neutral } \\
3\end{array}$ & $\begin{array}{l}\text { Agree } \\
4\end{array}$ & $\begin{array}{l}\text { Strongly } \\
\text { Agree } \\
5\end{array}$ & Comments \\
\hline 1. & $\begin{array}{l}\text { allowed me to see others' weekly accomplishments motivated me } \\
\text { to seek out similar leaming experiences }\end{array}$ & & & & & & \\
\hline 2 . & $\begin{array}{l}\text { featured planning for the following clinical week (s) helped me } \\
\text { plan my own experience for my next clinical }\end{array}$ & & & & & & \\
\hline 3. & $\begin{array}{l}\text { featured weekly clinical assignments helped me to focus and } \\
\text { complete those assignments on time }\end{array}$ & & & & & & \\
\hline 4. & $\begin{array}{l}\text { made me uncomfortable sharing my weekly clinical } \\
\text { accomplishments with my clinical group members }\end{array}$ & & & & & & \\
\hline 5. & $\begin{array}{l}\text { made me uncomfortable sharing my weekly activities to be } \\
\text { accomplished with my clinical group members }\end{array}$ & & & & & & \\
\hline 6. & $\begin{array}{l}\text { helped me to develop realistic clinical goals for the following } \\
\text { week }\end{array}$ & & & & & & \\
\hline 7. & $\begin{array}{l}\text { helped me achieve at the same level as or higher than the rest of } \\
\text { my clinical group members }\end{array}$ & & & & & & \\
\hline 8. & was a way of connecting with clinical group members & & & & & & \\
\hline 9. & was a way of connecting with clinical faculty & & & & & & \\
\hline 10. & $\begin{array}{l}\text { assisted me in my clinical continuity and clinical follow-up } \\
\text { needs }\end{array}$ & & & & & & \\
\hline 11. & $\begin{array}{l}\text { as a clinical feedback and communication strategy it should be } \\
\text { continued with other clinical groups }\end{array}$ & & & & & & \\
\hline
\end{tabular}

Please state any comments related to the experience of getting written clinical synopsis on a weekly basis:

Thank you!

Figure 2: Feedback on clinical teaching tool: wcs survey tool - from students who received weekly clinical synopsis 


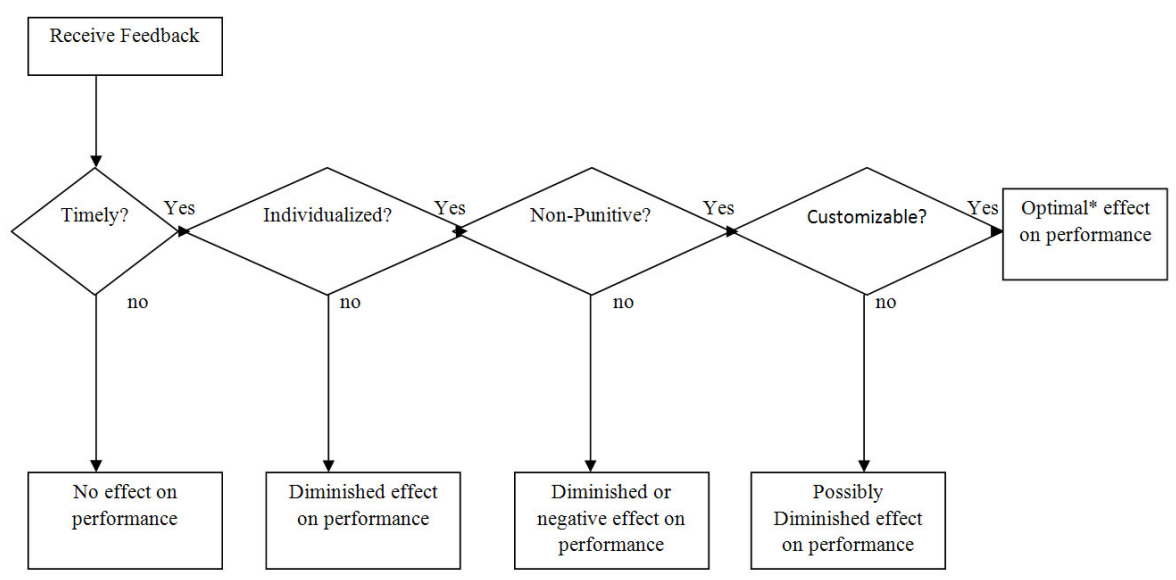

Figure 3: A model of actionable feedback by Hysong, Best, \& Pugh, 2006

\section{Methods}

The WCS pilot project was an IRB exempted process since it evaluated a clinical teaching strategy for quality improvement in clinical teaching. Two clinical faculty teaching two clinical groups each used WCS, an innovative clinical teaching strategy for six weeks. The strategy was used at the end of each clinical week of 12 clinical hours. Faculty wrote the WCS and shared it with the whole group through email. In this project, quantitative and qualitative methods were used to understand students' views about the WCS survey tool and the WCS strategy. Prior to quantitative data collection, the content validity of the instrument was established by three experienced clinical faculty who developed, reviewed, and mutually agreed on each of the WCS survey items to ensure it represented all the facets of the intent of the clinical synopsis. Since the survey was developed and administered for the first time it was important to gather the views of students who filled it out twice, prior to WCS's introduction and after its implementation. Hence, quantitatively, students' responses to the pre-WCS and post-WCS surveys were compared. In addition, the WCS survey's internal consistency reliability was determined. Qualitative data were collected from students' written comments on the pre-WCS and post-WCS surveys and from the two focus groups, one from each clinical faculty $(n=3$ and $n=2)$. Students' perceptions were elicited on the WCS tool: whether the survey items were understandable and clear; if the items comprehensively captured the intent of the WCS including face validity; and views about using the 5-point Likert scale. Both focus group interviews were conducted by a research faculty who was not involved in the development and implementation of the WCS.

\section{Results}

The participants were thirty undergraduate nursing students who were enrolled for six weeks ( 2 clinical days per week) in an inpatient psych-mental health nursing clinical during the winter term, 2014. Chronbach's alpha was calculated

Published by Sciedu Press to determine the internal consistency reliability of the WCS survey. For the pre-WCS survey, the Cronbach's alpha was .808. The post-WCS survey had a Cronbach's alpha of .795 . These Chronbach's alphas were acceptable which supported that the items of the surveys fit together quite well.

\subsection{Quantitative findings}

Quantitative findings resulted from comparisons between the pre and post-WCS surveys of the four clinical groups. Descriptive statistics were used to examine the measure of central tendency $($ mean $=\mathrm{M})$ and the measure of variability ( standard deviation $=S D)$. There were no missing values. Means and standard deviations were calculated for the four clinical groups both prior to WCS's introduction and after its implementation. The findings are summarized in Table 1.

The means of four WCS survey items $(1,6,8$, and 10 respectively) had a negative change from pre-to post-WCS including: a) seeing others' accomplishments motivated me to seek out similar learning experiences; b) helped me develop realistic clinical goals for the following week; c) was a way of connecting with clinical group members; and d) assisted in my clinical continuity and clinical follow-up needs. The means of the remaining six items had a positive change from pre-to post-WCS which indicated students' positive perceptions of the WCS. Item 11 of the post-WCS survey asked, "as a clinical feedback and communication strategy it should be continued with other clinical groups"; students highly supported its use for future clinicals (see Table 1). However, to determine whether or not there were significant differences (alpha $=.05$ ) between the pre-WCS survey item means and the post-WCS survey item means, the Mann Whitney Test, a non-parametric test, for two independent groups was conducted (see Table 2). Only two items ( $1 \& 3$ respectively) showed significant differences including: "seeing others' weekly accomplishments motivated me to seek out a similar experience"; and "helped to focus and complete assignments on time". 
Table 1: Means and standard deviations of fours groups' pre- and post- WCS surveys

\begin{tabular}{|c|c|c|c|c|}
\hline Weekly Clinical Synopsis Survey Scale Items & Pre \& Post & $\mathbf{N}$ & $\mathbf{M}$ & SD \\
\hline \multirow{2}{*}{$\begin{array}{l}\text { 1) Seeing others' weekly accomplishments motivates me to seek out similar } \\
\text { learning experiences }\end{array}$} & Pre & 30 & 4.00 & .78 \\
\hline & Post & 30 & 3.43 & 1.13 \\
\hline \multirow{2}{*}{ 2) Helps me plan my own experience for my next clinical } & Pre & 30 & 4.43 & .56 \\
\hline & Post & 30 & 4.46 & .81 \\
\hline \multirow{2}{*}{ 3) Helps me focus and complete assignments on time } & Pre & 30 & 4.10 & .88 \\
\hline & Post & 30 & 4.63 & .55 \\
\hline \multirow{2}{*}{$\begin{array}{l}\text { 4) Makes me uncomfortable sharing my weekly accomplishments with my clinical } \\
\text { group members }\end{array}$} & Pre & 30 & 4.00 & 1.11 \\
\hline & Post & 30 & 4.30 & .98 \\
\hline \multirow{2}{*}{$\begin{array}{l}\text { 5) Makes me uncomfortable sharing my weekly activities to be accomplished with } \\
\text { my clinical group members }\end{array}$} & Pre & 30 & 3.90 & 1.02 \\
\hline & Post & 30 & 4.36 & .88 \\
\hline \multirow{2}{*}{ 6) Helps me develop realistic clinical goals for the following week } & Pre & 30 & 4.20 & .66 \\
\hline & Post & 30 & 4.06 & .94 \\
\hline \multirow{2}{*}{ 7) Helps me achieve at the same level as or higher than the rest of my clinical group } & Pre & 30 & 4.10 & .71 \\
\hline & Post & 30 & 4.13 & .86 \\
\hline \multirow{2}{*}{ 8) A way of connecting with clinical group members } & Pre & 30 & 3.83 & 1.01 \\
\hline & Post & 30 & 3.46 & 1.22 \\
\hline \multirow{2}{*}{ 9) A way of connecting with clinical faculty } & Pre & 30 & 3.96 & .808 \\
\hline & Post & 30 & 4.00 & .982 \\
\hline \multirow{2}{*}{ 10) Assists in my clinical continuity and clinical follow-up needs } & Pre & 30 & 4.43 & .678 \\
\hline & Post & 30 & 4.23 & .817 \\
\hline \multirow{2}{*}{$\begin{array}{l}\text { 11) As a clinical feedback and communication strategy it should be continued with } \\
\text { other clinical groups }\end{array}$} & Pre & N/A & N/A & N/A \\
\hline & Post & 30 & 4.40 & .621 \\
\hline
\end{tabular}

Table 2: Comparison of the 2-independent samples means (pre-and post-WCS survey items) using the Mann Whitney Test

\begin{tabular}{|c|c|c|c|c|}
\hline Weekly Clinical Synopsis Survey Scale Items & $\begin{array}{l}\text { Mann- } \\
\text { Whitney U }\end{array}$ & $\begin{array}{l}\text { Wilcoxon } \\
\text { W }\end{array}$ & $\mathbf{Z}$ & $\begin{array}{l}\text { Asymp. Sig. } \\
\text { (2-tailed) }\end{array}$ \\
\hline $\begin{array}{l}\text { 1) Seeing others' weekly accomplishments motivates me to seek out similar } \\
\text { learning experiences }\end{array}$ & 319.00 & 784.00 & -2.052 & $.040^{*}$ \\
\hline 2) Helps me plan my own experience for my next clinical & 407.00 & 872.00 & -.724 & .469 \\
\hline 3) Helps me focus and complete assignments on time & 293.50 & 758.50 & -2.567 & $.010^{*}$ \\
\hline $\begin{array}{l}\text { 4) Makes me uncomfortable sharing my weekly accomplishments with my clinical } \\
\text { group members }\end{array}$ & 370.50 & 835.50 & -1.273 & .203 \\
\hline $\begin{array}{l}\text { 5) Makes me uncomfortable sharing my weekly activities to be accomplished with } \\
\text { my clinical group members }\end{array}$ & 327.50 & 792.50 & -1.944 & .052 \\
\hline 6) Helps me develop realistic clinical goals for the following week & 431.00 & 896.00 & -.306 & .760 \\
\hline 7) Helps me achieve at the same level as or higher than the rest of my clinical group & 427.50 & 892.50 & -.357 & .721 \\
\hline 8) A way of connecting with clinical group members & 374.00 & 838.00 & -1.180 & .238 \\
\hline 9) A way of connecting with clinical faculty & 425.50 & 890.50 & -.393 & .694 \\
\hline 10) Assists in my clinical continuity and clinical follow-up needs & 394.00 & 859.00 & -.909 & .363 \\
\hline
\end{tabular}
${ }^{*} p<.05$

\subsection{Qualitative findings}

Qualitative findings resulted from analyzing students' written comments on the pre-WCS and post-WCS surveys and from the two focus groups eliciting students' perceptions of the WCS tool. Firstly, students made comments on the WCS strategy in writing both prior to and after its imple- 
mentation. Of 30 students, 10 shared their views about the WCS prior to receiving it. Several students feared that it might increase their clinical workload or that it would create unhealthy competition among students. Most students, however, anticipated that the WCS would be very helpful. For example, many anticipated that it would help them be better organized, increase their clinical efficiency, be better prepared for clinicals, and motivate to seek out learning experiences.

Students were asked to fill out a WCS survey after they were introduced to the WCS strategy. Of 30 students, 26 shared that the WCS was extremely helpful. It created an opportunity for them to reflect on their clinical week and on their accomplishments. In addition to their accomplishments they wrote that it helped them to be better organized, prepared, and ready for the upcoming clinical week(s). It assisted them in making decisions about their long term and weekly clinical goals. It also helped them feel at ease and minimized their feeling of being overwhelmed that is associated with remembering clinical related activities/assignments and not knowing what is expected of them. It brought the clinical group to the same page and kept them on track. However, learning about their clinical group members' accomplishments was not the most significant factor in reviewing their WCS surveys. They recommended that WCS be continued in future clinicals. Finally, a couple of students commented on the length of the synopsis and suggested that it could be shortened and formatted to be more reader friendly.

Secondly, the results of the two focus group interviews elicited students' perceptions of the WCS survey tool and the WCS strategy. During a focus group students were asked to describe what they understood to be the meaning of each item. They reported understanding each of the WCS items and were able to communicate the intent of each of the items. They denied that any relevant items were missing from the survey but suggested merging WCS survey items 2,6 , and 10 because they were similar in content. Students found the 5-point Likert scale was appropriate to use, "I think it was a good way to measure... it was an accurate way as well, that it gave you the option of that you feel very strongly about it, or you just feel strong about it overall."

Students unanimously agreed that they found the WCS strategy to be helpful and relevant to their clinical learning, "I thought it was very helpful, it kind of wrapped the whole week up in a nutshell, as there is so much that goes on at clinical, it is nice to reflect back on it a couple of days afterwards." Students found reviewing their peers' accomplishments helpful if they were unique or out of the ordinary clinical experiences; otherwise they just skipped over them. They suggested that the section on accomplishments could be more helpful if the accomplishments were elaborated in terms of what a student learned from the experience. They shared, however, that seeing others accomplishments created an opportunity for them to think about taking them further than what others had done. According to one student,

I see in the document that somebody worked with the clinical care coordinator or someone had this experience, they were able to do it, which was giving us an example of what someone did which we should strive to do. Sometimes hearing about what other people did gave us the idea to try to do that as well.

They recommended that the accomplishments section be more concise and provide a list of activities they could possibly accomplish in their following clinical week. Regarding accomplishments to be achieved, some students shared that they felt pressured seeing that their peers had already accomplished a clinical task or if they had missed an opportunity.

Students valued the role of the WCS for keeping them informed about their weekly expectations regarding assignments and timelines. They agreed that the WCS assisted them greatly in clinical planning, goal setting, and clinical continuity and follow-up.

Not everyone viewed WCS as a way of connecting with other clinical group members because connecting via chat groups or exchanging emails was viewed as a more interactive process. However, they expressed that WCS kept them connected in a way because they were informed and up-todate about clinical related activities and kept them on the same page. According to one student, "Everybody thought, I think that we're all basically similar, no one was outshining another, we were all at the same level of understanding. If one person is confused, it was helpful to have everyone else know what to do and help that one person." Regarding the role of WCS in creating an open communication link with faculty, students agreed that they felt connected with the faculty. Because faculty created the weekly synopsis giving them the feeling that faculty knew what they were doing in the clinical setting.

Students commented on WCS's role in decreasing their worries about trying to write down everything faculty told them about clinical expectations and clinical assignments since they knew they would get this information in writing following each clinical. Hence, the clinical conference time focused more on discussing clinical related learning experiences instead of stating and repeating assignments, guidelines, the weekly clinical focus and expectations. According to one student “... I had an overall good experience with it, it helped because we never had to worry about jotting down notes while [the clinical instructor] was talking, so we could actually focus on what she was saying. I think that was the most helpful part."

Students also mentioned that faculty might consider asking 
them whether or not they read their WCS on a weekly basis, and if they read it completely. They further suggested reorganizing it in a way that new information be given at the beginning of the WCS document. For example, one student mentioned that "... shortening it, each week there is some repetitive information, so may be by putting the new information at the top we could just go through what was different instead of surfing through the whole thing."

\section{Discussion}

Quantitatively two WCS survey items means were significantly different at pre-WCS and post-WCS. One item, "seeing others' weekly accomplishments motivates me to seek out similar experiences", had a significant negative change. The other item, "helps to focus and complete assignments on time" showed a positive change score.

The negative change on the item 'seeing others' weekly accomplishments motivates me to seek out similar experiences" indicated that seeing others accomplishments did not motivate them to seek out similar learning experiences. This could be that students' exposure over time of seeing others' weekly accomplishment reduced the need to see those accomplishments as time progressed. It is not known if there was a threshold effect or there was a significant decrease in their rating of this item because it may not have been useful in the initial stages of their clinical experience. Nonetheless, this quantitative finding, related to seeing others weekly accomplishments matched students' qualitative feedback on the WCS. Though they shared mixed views about seeing others' weekly accomplishments that they had skimmed over, it made them think about accomplishing more than what others had done. On the other hand, the positive change in the score on the item "helps us to focus and complete assignments on time" indicated that WCS significantly helped students focus and complete assignments on time which again matched their qualitative comments that WCS kept them informed about their weekly expectations regarding assignments and timeliness. The remaining items were not significant. This could be due to the fact that students anticipated that WCS would be a positive teaching strategy and that their thoughts and views were sustained after being exposed to the strategy. It is safe to conclude that students had a positive learning experience using WCS. Another possible explanation for the non-significant results could be due to the small sample size and the range of response options. Hence, there is a need to implement WCS with a larger group of students and possibly increase the range of response options to deal with the potential impact of a ceiling effect. Finally, considering the high internal consistency reliability of the pre-and post-WCS survey tools and students' qualitative feedback about these tools in this pilot project indicate that they could be used in a future project with a larger sample size.
Qualitatively, students were positive about their experiences with the WCS as a teaching tool. Their perspectives about the WCS strategy were sustained after being exposed to the strategy. Interestingly, students' comments with respect to whether the WCS created a connection among students were not as positive as expected. Students reported that there were other types of communication that promoted connection among them such as chat, emails, and post-conference discussions. It appears as though other teaching strategies such as small group activities would likely facilitate greater connection and interpersonal relationships. Students' comments with respect to WCS creating connection among them yielded important insights in that WCS served a different purpose than creating connections. Hence, students' specific comments about how WCS actually functioned on an ongoing basis helped them to rethink the purpose to create connection. Nonetheless, the WCS was another mechanism that promoted a connection between each student and their clinical faculty. Following receiving WCS, it prompted students to ask their clinical faculty questions about their clinical week's planning such as developing clinical goals, working on their assignments and clinical activities to name a few. Faculty felt more connected with each student as they knew what each student was working on and would be working on in the clinicals. Similarly, students seemed to feel comfortable approaching faculty and asking them questions related to their clinical planning. Such reciprocity helped faculty and students be continuously engaged on clinical related matters. Faculty felt more connected with each student in terms of clinical related tasks at hand by the ongoing continuous engagement.

The WCS helped students organize by providing them a structure for clinicals and creating clinical goals. Having a structure and organization that was consistent, organized, and standardized limited students' anxiety about what to expect in clinicals and what to expect from clinical faculty. In addition, it limited clinical post-conference time asking questions regarding assignments and expectations as students knew this content would be followed up in writing. Hence, they did not feel the pressure of capturing every word that the faculty said. They felt they were more available mentally to actively participate in the discussions with faculty on clinical assignments and expectations.

The WCS served faculty in several ways as well. The WCS helped faculty teaching two clinical groups a week to be organized and timely in giving feedback so that all students in both clinical groups were given an opportunity to accomplish their clinical competencies. Since the WCS summarized everything, it facilitated faculty's organization and effectiveness in that it was the only document needed for planning what each individual student needed to accomplish in the following clinical. The use of the WCS seemed to be a helpful clinical teaching tool. Initially the writing of the WCS was labor intensive particularly for the first clinical 
week as it took several hours of clinical planning. However, the benefits of such planning outweighed the efforts as clinical faculty felt confident that they were prepared for the coming clinical week(s). The use of the WCS seemed to address some of clinical faculty's struggles identified in the literature. For example, the WCS assisted faculty in providing timely ${ }^{[1-4]}$ input on their students' strengths and accomplishments. Faculty also noticed that throughout their clinical students did not have many queries about clinical assignments which could probably be because all the clinical assignments' criteria were outlined in their first WCS and reinforced on a weekly basis. The WCS definitely played an important role in creating and strengthening faculty-student connection and facilitated faculty's partnership with students in their learning journey which was needed for an effective working relationship. ${ }^{[15]}$ The WCS focused only on providing input on students' clinical accomplishments and were written with a positive tone which contributed to enhancing their performance ${ }^{[7]}$ and motivating ${ }^{[8-12]}$ them to actively participate in their clinical planning, developing their clinical goals and making an effort to accomplish them. Students validated how much WCS assisted them in their clinical planning and developing their clinical goals. Involving students to actively participate in their learning is supported in the literature and is identified as an essential consideration in planning a nursing curriculum. ${ }^{[17]}$ Findings indicated that not all students viewed seeing theirs or colleagues' accomplishments as helpful; clinical faculty realized that students and faculty might differ in their views of what constitutes an accomplishment in mental health nursing practice. Faculty also realized the importance of teaching students to understand the gravity and pervasiveness of mental illness so that students can appreciate the importance of their roles as care providers and see their clinical experiences of working with clients with mental illness as valuable. Since the primary focus of the WCS was not to evaluate students' clinicals, however keeping track of each student's progress in writing through the WCS greatly helped faculty in writing summative evaluations as students' week by week accomplishments were outlined in it.

Conceptually the findings of the WCS project were consistent with the components of "a model of actionable feedback" by Hysong, Best, and Pugh. ${ }^{[16]}$ For example, the component of "timeliness" occurred when faculty provided feedback on students' accomplishments using WCS within 24-48 hours each clinical week. Thus, students felt more prepared for clinicals and more directed towards achieving clinical and written assignment expectations. Feedback on clinical accomplishments was shared in writing with the whole group, yet the feedback was "individualized" as each student received weekly feedback on one or more of the WCS' components such as clinical accomplishments and input about upcoming assignments. Use of the WCS provided "non-punitive" feedback. The content focused on accomplishments and clinical expectations in a way that motivated

Published by Sciedu Press students to be actively involved in their clinical planning and clinical goal setting. Students were mobilized to approach faculty with questions that guided learning activities. The WCS engaged students in a way that focused on their particular learning needs and accomplishments. To some extent, customizability was evident as students used the feedback to reflect and act on their personal clinical learning activities. It is important to appreciate that the WCS strategy simultaneously and inherently integrated the four components of "a model of actionable feedback" without any particular hierarchy.

This pilot project was not without limitations. Using a very small sample limited the accuracy, validity and ability to generalize the findings. Future studies need to be done with a larger sample size of students and the involvement of multiple clinical faculty using the WCS strategy as a means of controlling for the role of faculty on student's experiences with this clinical tool. Also, the project findings would have been more rigorous if each student's pre-WCS survey were paired with their post WCS survey. This could have eliminated the individual differences that occurred between subjects. Lastly, since the WCS strategy was implemented only with students in a psychiatric clinical experience, it is not known how the WCS strategy would play out in other clinical practice settings. In spite of these limitations, the findings suggested that WCS was viewed as a beneficial clinical teaching strategy by both students and faculty and should be further evaluated.

\section{Conclusion}

The initial testing of this innovative clinical teaching strategy of WCS indicated that it has great potential to assist students in their weekly clinical goals and clinical planning which students endorsed in their feedback on the WCS survey tool as well. Similarly, clinical faculty found it to be extremely helpful in their overall and weekly clinical planning to assist students in their clinical planning and determining clinical goals and clinical learning opportunities. It created a meaningful and ongoing working connection between faculty and each individual student that motivated students and that hopefully could assist in desired behavioral changes. The premise of the WCS is conceptually sound and able to address faculty's struggles related to providing ongoing clinical feedback and guidance to a large extent. In conclusion the use of the WCS, a clinical teaching strategy, is mutually beneficial to both students and faculty though it may have some limitations. The WCS strategy should be further tested to develop more knowledge about its effectiveness and areas needing modification.

\section{Acknowledgements}

We would like to thank the nursing students who participated in the pilot project for their valuable time, interest and commitment. Sincere thanks to Dr. Beverly Rosenthal 
for her persistent support in reviewing every draft of this manuscript. Finally, thanks to Bidisha Gosh for her statistical support in this project.

\section{Conflicts of Interest Disclosure}

The author declares that there is no conflict of interest statement.

\section{References}

[1] Cantillon P, Sargeant J. Teaching rounds: giving feedback in clinical settings. British Medical Journal [Internet]. 2008; 337: 1292-94. Available from: http: //www.scribd.com/doc/44184574/Giving-Feedback-i n-Clinical-Settings-Cantillon-P-Sargeant-J

[2] Ende J. Feedback in clinical medical education. Journal of American Medical Association. 1983; 250(6): 777-81. http://dx.doi .org/10.1001/jama.1983.03340060055026

[3] Glover PA. 'Feedback. I listened, reflected and utilized': third year nursing students' perceptions and use of feedback in the clinical setting. International Journal of Nursing Practice. 2000; 6(5): 247-52. http://dx.doi.org/10.1046/j.1440-172x.2000.00218.x

[4] Koh LC. Refocusing formative feedback to enhance learning in preregistration nurse education. Nurse Education in Practice. 2008; 8: 223-30. Available from: http://www.sciencedirect.com/sc ience/article/pii/S1471595307000807

[5] Slowey M, Watson D. Education and the life course: society for research into higher education. Hounsell D, student feedback, learning and development. Maidenhead: Open University Press, 2003.14p. Available from: http://books.google.com/books?hl=en\&l $r=\& i d=j h 46 B m z u K i k C \& o i=f n d \& p g=P A 67 \& d q=S t u d e n t+f$ eed back, +learnig+and+development\&ots=Je7TRGMVKc\&sig=U v5xFBHCh6ADz1g5lIDsaI6fqj s\#v=onepage\&q=Student $\% 20 f$ eeback $\% 2 \mathrm{C} \% 20$ learning $\% 20$ and $\% 20$ development\&f=false

[6] Clynes MP, Raftery SEC. Feedback: an essential element of student learning in clinical practice [Internet]. Nurse Education in Practice. 2008; 8: 405-11. Available from: http://www.sciencedirect. com/science/article/pii/S1471595308000206\#

[7] Plakht Y, Shiyovich A, Nusbaum L, Raizer H. The association of positive and negative feedback with clinical performance, self-evaluation and practice contribution of nursing students [Internet]. Nurse Education Today. 2013; 33: 1264-68. Available from: http://www.sciencedirect.com/science/article/ pii/S0260691712002596

[8] Mogan J, Knox JE. Characteristics of 'best' and 'worst' clinical teachers as perceived by university faculty and students [Inter- net]. Journal of Advanced Nursing. 1987; 12(3): 331-37. Available from: http://wordpress.up.edu/clinicalfaculty/f iles/2013/03/Best-and-worst-clinical-teachers .pdf

[9] Nehring V. Nursing clinical teacher effectiveness inventory: A replication study of the characteristics of 'best' and 'worst' clinical teachers as perceived by nursing faculty and students. Journal of Advanced Nursing. 1990; 15(8): 934-940. http://dx.doi.org/10. 1111/j.1365-2648.1990.tb01949.x

[10] Sieh S, Bell SK. Perception of effective clinical teachers in associate degree programs. Journal of Nursing Education. 1994; 33(9): 389-94.

[11] Wilson ME. Nursing student perspective of learning in a clinical setting. Journal of Nursing Education. 1994; 33(2): 81-86.

[12] LI MK. Perceptions of effective clinical teaching behaviours in a hospital-based nurse training programme. Journal of Advanced Nursing. 1997; 26: 1252-1261. http://dx.doi.org/10.1046/j .1365-2648.1997.00470.x

[13] Bradbury-Jones C, Irvine F, Sambrook S. Empowerment of nursing students in clinical practice: spheres of influence. Journal of Advanced Nursing. 2010; 66(9): 2061-70. Available from: http://onlinelibrary.wiley.com/doi/10.1111/j . 1365-2648.2010.05351.x/pdf

[14] Cederbaum J, Klusaritz HA. Clinical instruction: using the strengths-based approach with nursing students. Journal of Nursing Education. 2009; 48(8): 422-28. PMid:19681530 http://dx.doi . org/10.3928/01484834-20090518-01

[15] Lee WS. Cholowski K, Williams AK. Nursing students' and clinical educators' perceptions of characteristics of effective clinical educators in an Australian university school of nursing. Journal of Advanced Nursing. 2002; 39(5): 412-20. http://dx.doi.org/10. $1046 / j .1365-2648.2002 .02306 . x$

[16] Hysong SJ, Best RG, Pugh JA. Audit and feedback and clinical practice guideline adherence: making feedback actionable [Internet]. Implementation Science. 2006; 1: 9. Available from: http://ww w. biomedcentral . com/content/pdf/1748-5908-1-9.pdf

[17] Sharif F, Masoumi S. A qualitative study of nursing student experiences of clinical practice [Internet]. BMC Nursing, 2005; 4(6). Available from: http://www.biomedcentral.com/content/ pdf/1472-6955-4-6.pdf 